\title{
Reflexiones sobre la Importancia de la Modelación Matemática como Estrategia Inductora de Competencias Estadísticas
}

\author{
Andréa Pavan Perin 1 \\ andreapavanperin@gmail.com \\ https://orcid.org/0000-0002-2791-7682 \\ Celso Ribeiro Campos ${ }^{2}$ \\ crcampos@pucsp.br \\ https://orcid.org/0000-0001-7371-2437 \\ ${ }^{1}$ Faculdade de Tecnologia de São Paulo \\ ${ }^{2}$ Pontifícia Universidade Católica de São Paulo - Brasil
}

Recibido: 2020-08-22; Aceptado: 2020-11-17

\section{Resumen}

Según los preceptos de la Educación Estadística, el aprendizaje del contenido estadístico depende del desarrollo de la alfabetización estadística, el razonamiento y las habilidades de pensamiento. Además de esto, hemos desarrollado investigaciones que demuestran que a este rol se le debe sumar la competencia crítica, ya que tiene una fuerte conexión con la idea de formar estudiantes capaces de ejercer derechos y deberes inherentes a la ciudadanía, además de tener aspectos comunes con otras competencias. Al sumar la competencia crítica, se construyen las bases de la Educación Estadística Crítica, en la que la principal estrategia pedagógica es el Modelado Matemático. Nuestro objetivo en este estudio es mostrar cómo el Modelado Matemático puede actuar en la enseñanza / aprendizaje de la Estadística como inductor o facilitador del desarrollo de las competencias mencionadas. Analizamos las etapas de Modelización descritas por Burack (2004) y mostramos la adherencia de esta estrategia a los requisitos necesarios para el desarrollo de las cuatro competencias mencionadas, mostrando así su importancia para la Educación Estadística Crítica.

Palabras-clave: educación estadística, educación crítica, modelado matemático, competencias

\section{Reflexões sobre a importância da Modelagem Matemática como estratégia indutora de competências estatísticas}

\section{Resumo}

De acordo com os preceitos da Educação Estatística, o aprendizado dos conteúdos estatísticos depende do desenvolvimento das competências de literacia, raciocínio e pensamento estatísticos. Complementarmente a isso, temos desenvolvido de pesquisas mostrando que a competência crítica deve ser agregada a esse rol, pois tem forte ligação com a ideia de formar estudantes aptos a exercer direitos e deveres inerentes à cidadania, além de ter aspectos comuns com as demais competências. Ao agregar a competência crítica, constrói-se as bases da Educação Estatística Crítica, na qual a principal estratégia pedagógica é a Modelagem Matemática. Nosso objetivo neste estudo é mostrar como a Modelagem Matemática pode atuar no ensino/aprendizagem de Estatística como indutora ou facilitadora do desenvolvimento das 
competências mencionadas. Analisamos as etapas da Modelagem descritas por Burack (2004) e mostramos a aderência dessa estratégia com os requisitos necessários para o desenvolvimento das quatro competências mencionadas, mostrando assim a sua importância para a Educação Estatística Crítica.

Palavras-chave: educação estatística, educação crítica, modelagem matemática, competências

\title{
Reflections on the Importance of Mathematical Modeling as an Inducing Strategy for Statistical Competences
}

\begin{abstract}
According to the precepts of Statistics Education, learning statistical content depends on the development of statistical literacy, reasoning, and thinking skills. In addition to this, we have developed research that shows that critical competence must be added to this role, since it has a strong connection with the idea of training students capable of exercising rights and duties inherent to citizenship, in addition to having common aspects with other skills. By adding critical competence, the foundations of Critical Statistics Education are built, in which the main pedagogical strategy is Mathematical Modelling. Our objective in this study is to show how Mathematical Modelling can act in the teaching / learning of Statistics as an inducer or facilitator of the development of the aforementioned competences. We analyze the modeling stages described by Burack (2004) and show the adherence of this strategy to the necessary requirements for the development of the four aforementioned competencies, thus showing its importance for Critical Statistics Education.

Keywords: statistics education, critical education, mathematical modelling, competences
\end{abstract}

\section{Introdução}

A Estatística, por ser uma ciência de análise de dados, está presente em diversos os contextos. Por essa razão, compreendê-la é fundamental para que as pessoas possam entender, avaliar e posicionar-se frente aos dados estatísticos que circulam nos mais variados meios de comunicação.

Reconhecida a frequência da Estatística no cotidiano das pessoas, pesquisadores da área de Educação Estatística começaram a discutir a importância dessa ciência ser ensinada desde a educação básica até o ensino superior. Tal discussão foi pontuada, inicialmente, em dois documentos, sendo um da American Statistical Association (ASA) e um do National Council of Teachers of Mathematics (NCTM), publicados nos anos de 1960 e 1967, respectivamente. Dada a expressividade adquirida por esses documentos, a partir de 1989 revistas importantes da área de educação publicaram artigos que destacavam duas ações que mereceriam atenção: inserir a Estatística a todos os níveis escolares e dar maior atenção às formas de conduzir os processos de ensino-aprendizagem dessa ciência (Zieffler, Garfield \& Fry, 2018). 
No contexto brasileiro, a preocupação com os processos de ensino-aprendizagem de estatística também tem ganhado espaço nos documentos oficiais. No final da década de 1990, com a publicação dos Parâmetros Curriculares Nacionais, a Estatística e a Probabilidade foram incorporadas oficialmente à estrutura curricular da educação básica (Samá, 2018). Mais recentemente, a promulgação da Base Nacional Comum Curricular (Brasil, 2017) ratifica a inserção da Estatística e da Probabilidade na educação básica e sugere a abordagem de conceitos estatísticos por meio de situações da vida cotidiana, das ciências e da tecnologia (Cazorla, Silva \& Santana, 2018).

Tanto no contexto nacional como internacional, a divulgação desses documentos levou muitos pesquisadores a desenvolverem e aperfeiçoarem estudos voltados à Educação Estatística. As pesquisas nessa área têm avançado em todo o mundo e uma das grandes conquistas foi a identificação das competências estatísticas que devem ser desenvolvidas nos estudantes para uma aprendizagem efetiva dos conceitos dessa ciência. Nessa linha, foram identificadas as competências relacionadas ao pensamento estatístico, raciocínio estatístico e literacia (ou letramento) estatística. Uma primeira suposição, apresentada por Delmas (2002), foi a de que essas competências teriam partes em comum, formando um entrelaçamento, como mostra a figura 1 .

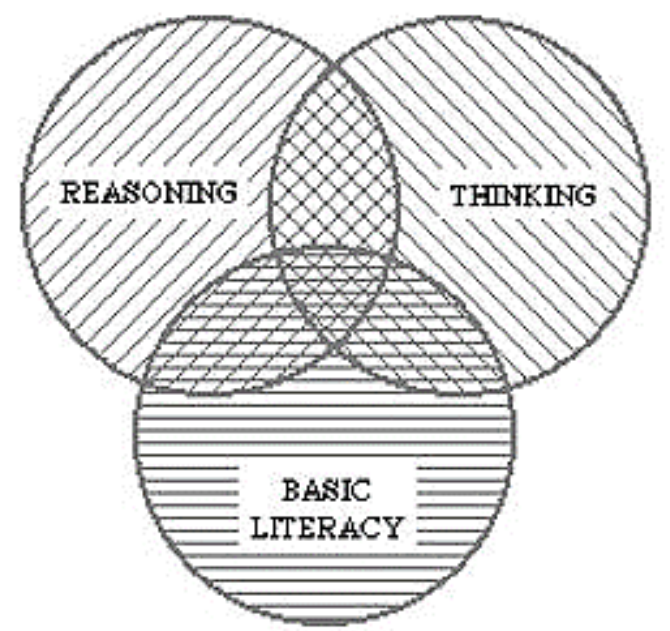

Figura 1: Domínios independentes com alguma intersecção (Delmas, 2002, p. 4)

O mesmo autor sugere também a possibilidade de a literacia ter um domínio mais abrangente, com as demais competências inseridas nela, conforme sugere a figura 2. 


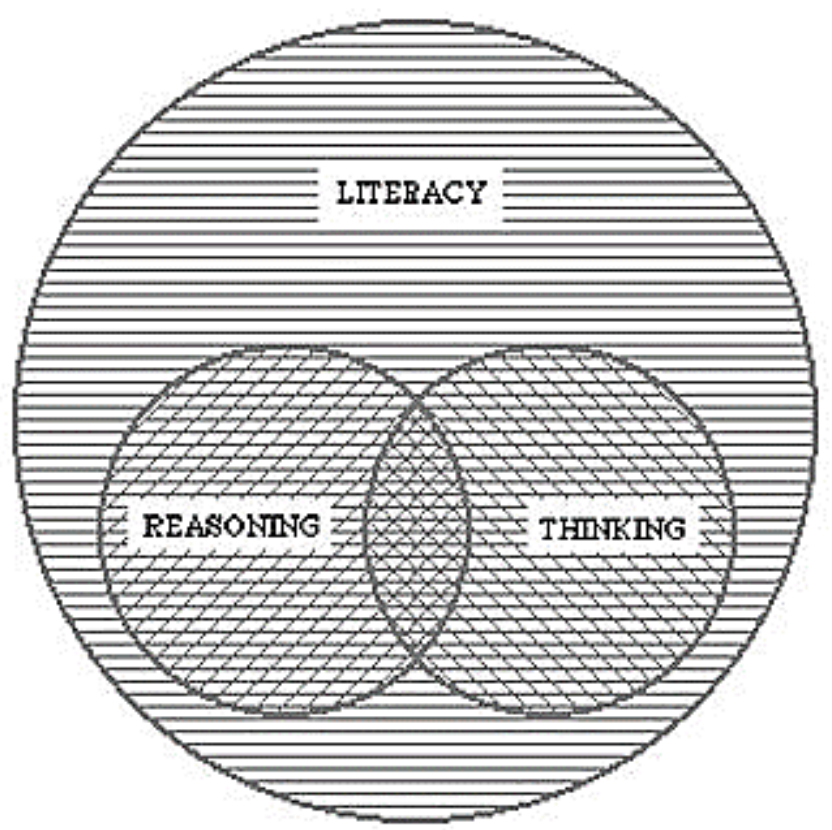

Figura 2: Raciocínio e pensamento contidos na literacia (Delmas, 2002, p. 4)

Essa segunda interpretação foi mais aceita pela comunidade acadêmica e passou-se a trabalhar com mais afinco no âmbito da literacia, buscando-se identificar seus determinantes, níveis de aprofundamento, como avaliar seu desenvolvimento, suas conexões com a modelagem matemática e com outros letramentos (Campos e Coutinho, 2019; Coutinho e Campos, 2018). Além disso, diversos autores (Campos et al., 2011; Perin, 2019) reforçaram que o desenvolvimento dessas competências é passível de maior sucesso quando os alunos experimentam todas as etapas de uma investigação estatística: formulação de questões; coleta de dados; análise de dados; interpretação e divulgação dos resultados. Essas etapas sugerem que as atividades de Estatística possuem uma relação próxima de um ambiente de aprendizagem denominado modelagem matemática na perspectiva da Educação Matemática (Campos, 2007; Campos, 2016; Machado, 2017; Soares, 2017; Trainotti, 2019). A modelagem matemática possibilita também o desenvolvimento de uma quarta competência, identificada em Campos (2007 e 2016) e em Perin (2019), que é a competência crítica.

O que buscamos neste artigo é responder a seguinte questão: Como uma atividade de modelagem matemática, estruturada de forma a desenvolver as competências do raciocínio e pensamento estatísticos, abarca o desenvolvimento da literacia estatística e, por consequência, exercita a competência crítica? Para atingir nosso objetivo de responder a essa questão, 
apresentamos as características de cada uma dessas competência e as diferentes concepções de modelagem matemática a fim situar o referencial teórico que sustenta a pesquisa. Na sequência, discorremos sobre a metodologia adotada para desenvolver o presente estudo, apresentamos o nosso quadro teórico e, por fim, evidenciamos de que forma essas competências caminham juntas numa atividade de modelagem matemática com o propósito de atingir o objetivo proposto nesse artigo.

\section{Metodologia}

De acordo com Almouloud e Silva (2019), pesquisar significa procurar respostas para certas indagações, de forma planejada, utilizando procedimentos sistemáticos, baseados no raciocínio lógico, no intuito de encontrar soluções para os problemas propostos mediante o emprego de métodos científicos. Ainda segundo os autores, o processo de pesquisa é um conjunto de operações sucessivas realizadas para coletar sistematicamente informações válidas sobre um fenômeno observável para explicá-lo ou compreendê-lo. Dessa forma, os procedimentos metodológicos têm por função a sistematização das etapas realizadas em um determinado estudo para assegurar a sua confiabilidade e validade. Nesse sentido, os procedimentos devem ser concebidos para construir os meios que permitem alcançar o objetivo geral da pesquisa.

Adicionalmente, assim como Coutinho e Campos (2019), entendemos a metodologia como sendo a linguagem estruturante do pensamento acadêmico/científico, ou seja, "aquilo que organiza o raciocínio lógico/analítico/cognitivo pertinente a uma argumentação formal cuja finalidade é a validação ou refutação de uma ou mais hipóteses" (p. 83).

Segundo Fiorentini e Lorenzato (2006), partindo de um problema ou da questão de investigação, existem dois modos de chegar às conclusões, quais sejam: por meio de uma pesquisa de campo ou de laboratório, a qual conduz à coleta e análise de dados/material empírico ou experimental; e por meio da pesquisa teórica ou bibliográfica, que surge com base na literatura, pesquisas ou estudos precedentes, na qual é preciso coletar/organizar dados ou documentos para um tratamento analítico de informações. A questão de pesquisa que ora buscamos responder se encaixa nesse segundo tipo descrito pelos autores. Complementarmente, dada a questão de investigação e os objetivos desta pesquisa, podemos dizer que é uma pesquisa de natureza qualitativa, pois o que se busca é o entendimento de ligações entre os elementos da 
Educação Estatística e da Modelagem Matemática. Sendo assim, a busca está direcionada à compreensão da manifestação desses elementos, e não ao tratamento quantitativo de dados.

Iniciamos nossa explanação sobre a importância do tema deste estudo citando a evolução que se sucedeu à publicação dos documentos da ASA e do NCTM. Citamos também alguns documentos brasileiros que reforçaram a importância do ensino de Estatística na educação básica, quais sejam os PCN e a BNCC. Tendo como ponto de partida esses documentos citados, vamos trilhar nosso caminho em busca da resposta à nossa questão de pesquisa por meio do nosso quadro teórico. Almouloud e Silva (2019) pontuam que o referencial teórico é a base que sustenta qualquer pesquisa científica, "esse referencial implica na perspectiva em que um problema será abordado, as diretrizes para sua elaboração e avaliação de sua relevância $a$ priori e a posteriori" (p. 49). Ainda segundo os autores, o referencial teórico pode garantir a sistematização do conhecimento, distinguindo-o do senso comum com base nos procedimentos usados na pesquisa.

O referencial teórico que nos permitirá alcançar o objetivo desta pesquisa começa com a descrição das competências de raciocínio e pensamento estatísticos. O raciocínio estatístico será analisado com base nos estudos de Pfannkuch (2018) e Biehler et al. (2018), entre outros. Já sobre o pensamento estatístico, nos basearemos principalmente nos estudos de Snee (1990, 1999) e Wild e Pfannkuch (1999). Feito isso, iremos estudar a Modelagem Matemática segundo a percepção de Burack (1992, 2004 e 2019), pontuando as características das diversas fases que compõem essa estratégia pedagógica. Gal (2002) nos dará suporte para a literacia estatística, enquanto as pesquisas de Skovsmose (2014), Campos (2007 e 2016) e de Perin (2019) darão sustentação à competência crítica.

\section{Literacia, raciocínio e pensamento estatístico.}

A literacia está relacionada à capacidade de ler e interpretar dados contidos em tabelas e gráficos, verificar se as conclusões presentes em uma informação podem ser obtidas com base nos dados disponíveis e compreender os conceitos envolvidos entre a inferência e a tomada de decisão. Essa competência envolve a análise conceitual de informações e postura crítica das demandas estatísticas presentes nos meios de comunicação e está ligada ao desenvolvimento do pensamento crítico sobre os dados.

A literacia estatística se refere também ao estudo de argumentos que usam a Estatística como referência, ou seja, à habilidade de argumentar usando corretamente a terminologia 
Estatística, além de habilidades importantes que podem ser usadas no entendimento de informações estatísticas. Para isso, inclui a capacidade de organizar dados, construir e apresentar tabelas, trabalhar com diferentes representações de dados e ainda considera o entendimento de conceitos, vocabulários, símbolos e as probabilidades como medidas da incerteza (Campos et al., 2011).

Gal (2002) propõe o que chama de modelo de literacia estatística, o qual pressupõe que a literacia requer a mobilização conjunta de componentes cognitivos e afetivos. O componente cognitivo é composto por cinco elementos de conhecimentos inter-relacionados, pois o entendimento da informação estatística requer não somente o conhecimento estatístico em si, mas outros que lhe são básicos. O segundo componente, afetivo, é composto por dois elementos, pois o entendimento da informação estatística depende da competência para propor perguntas e ativar uma postura crítica, que, por sua vez, envolve crenças e atitudes. Os componentes desse modelo com seus respectivos elementos estão organizados no Quadro 1.

Quadro 1 - Modelo de Literacia Estatística

\begin{tabular}{|c|c|}
\hline Elementos dos Conhecimento & Elementos de disposição \\
\hline Habilidade de letramento & Crenças e atitudes \\
Conhecimento estatístico & Posicionamento crítico \\
Conhecimento matemático & \\
Conhecimento contextual & \\
Questionamento crítico & \\
\hline
\end{tabular}

Fonte: Gal (op. cit., p. 4)

Perin (2019), explica que essa competência está associada ao uso que um indivíduo faz do conhecimento estatístico para compreender o que não está necessariamente explícito em uma informação estatística. Não se trata apenas de saber-fazer, mas de compreender o quê, como e por que fazer de determinada forma em um contexto específico, e, ao fazê-lo, ter ciência das implicações do que se faz.

$\mathrm{O}$ raciocínio está mais ligado à compreensão conceitual e à conexão de importantes ideias, como variação, distribuição, centro, dispersão, associação e amostragem ou combinação de ideias sobre dados e incerteza que conduzem a realização de inferência.

Para que os estudantes possam desenvolver essa competência, as tarefas em sala de aula devem ser preparadas com o objetivo de levar os alunos ao desenvolvimento de ideias estatísticas centrais. É necessário que elas conduzam ao aprofundamento da compreensão 
conceitual em Estatística, ao invés da aprendizagem de procedimentos e representações específicas. Algumas dessas ideias centrais, segundo Biehler et al. (2018) são:

Dados: o objetivo é perceber a necessidade dos dados para tirar conclusões e fazer avaliações. Aspectos ligados à obtenção de dados que sejam válidos devem ser também contemplados;

Distribuição: a ideia é levar os alunos a ter uma visão global dos dados de modo a desenvolverem a noção de distribuição;

Variabilidade e centro: deve-se incentivar a conjugação da análise de medidas de tendência central com a dispersão dos dados, medida, por exemplo, pela amplitude da amostra e pela amplitude interquartis;

Amostragem e inferência: saber como as amostras estão relacionadas com a população e o que pode ser inferido com base em uma amostra, levando os alunos a compreender que as decisões se baseiam em amostras.

Perin e Wodewotzki (2019), afirmam que o raciocínio estatístico concerne ao trabalho com as ferramentas estatísticas, não direcionado a saber operar com elas, mas atento aos seus significados mais profundos. É estar atento ao seu sentido, à mensagem subjacente a elas, principalmente no contexto em que são utilizadas.

Já o pensamento estatístico é caracterizado pela habilidade de relacionar dados quantitativos com situações concretas, explicitando-se o que os dados dizem sobre o problema, associando os modelos matemáticos à natureza contextual em que se envolvem. Tal competência torna-se evidente quando um aluno questiona sobre a melhor forma de obter dados, reflete sobre as variáveis envolvidas, demonstra ceticismo sobre a obtenção de tais dados, explora além do que os textos prescrevem, faz interpretações também em termos não estatísticos e questiona espontaneamente os dados e os resultados (Campos et al., 2011).

Wild e Pfannkuch (1999), após realizarem seus estudos sobre o pensamento estatístico concluíram que essa competência está baseada em quatro dimensões: ciclo investigativo, ciclo interrogativo, tipos de pensamento e disposições.

$\mathrm{O}$ ciclo investigativo refere-se à forma de agir e pensar durante uma investigação estatística. Esse ciclo foi adaptado por Wild e Pfannkuch (op. cit.) para problem, plan, data, analysis, conclusions (PPDAC), mostrados na figura 3. 


\section{Dimensão 1: O Ciclo Investigativo}

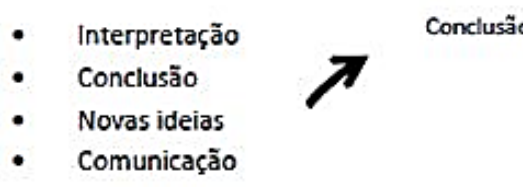

- Exploração dos dados

- Planejamento das análises

- Análises não planejadas

- Hipóteses e generalizações

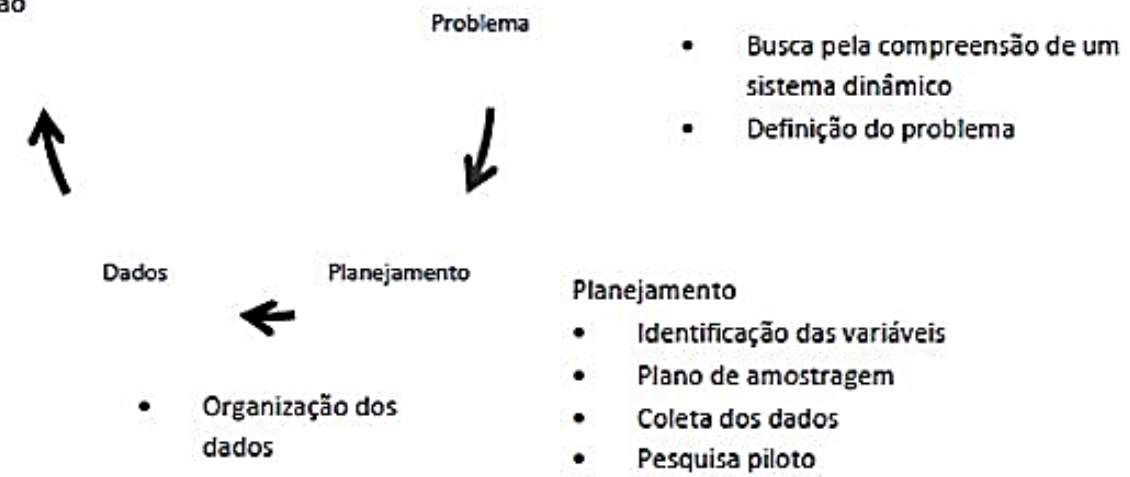

Figura 3: Dimensões do ciclo investigativo e atividades envolvidas (adaptado de Wild e Pfannkuch, 1999)

O ciclo interrogativo é um processo genérico do pensamento e constante durante a resolução de um problema estatístico, e seus componentes estão apresentados na figura 4. Relaciona-se ao levantamento de questões tanto no nível macro como no nível micro da pesquisa. Esse ciclo engloba cinco atividades: gerar ideias, que podem ser oriundas do contexto ou do conhecimento estatístico; buscar informações para dar continuidade à pesquisa; interpretar, processo que envolve os atos de ler, ver, ouvir, traduzir, resumir internamente, comparar e conectar; criticar, que envolve o ato de checar os pontos a favor e contra os resultados em mãos; julgar, questionando a confiabilidade das informações, a utilidade das ideias, praticidade dos planos, a conformidade com o contexto e o entendimento estatístico, a necessidade de outras pesquisas etc. 


\section{Dimensão 2: o ciclo interrogativo}

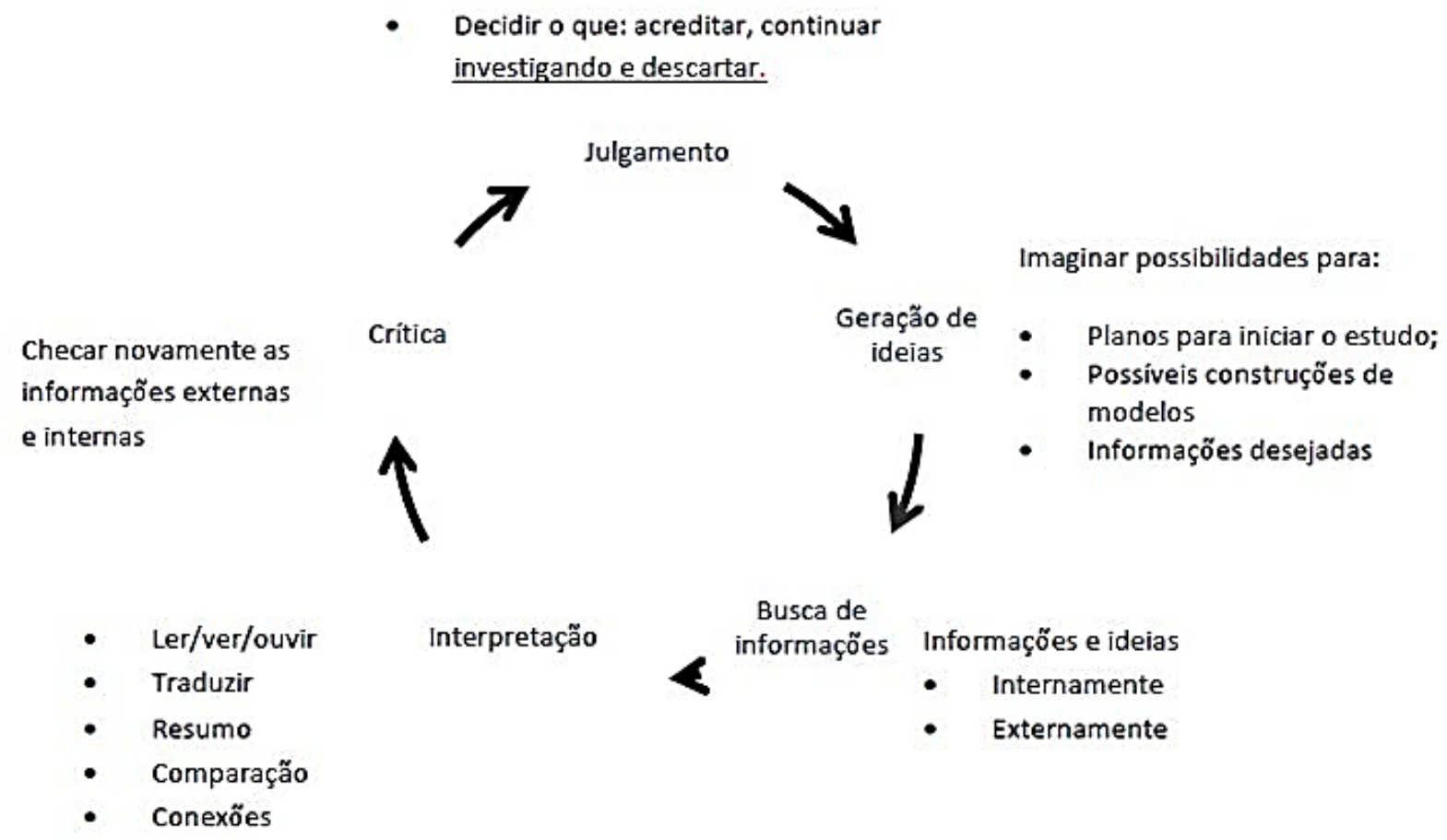

Figura 4: Dimensões do ciclo interrogativo e atividades envolvidas (adaptado de Wild e Pfannkuch, 1999)

A terceira dimensão, denominada tipos de pensamento, é composta por duas modalidades de pensamento: o geral e o fundamental. O pensamento geral refere-se ao planejamento do ciclo investigativo, visando a algumas estratégias que conduzem a investigação; elaboram-se questões do tipo: o que faremos? Como faremos? Temos dinheiro e material suficientes? Quais são os prazos? Os dados podem apresentar limitações? Já o pensamento fundamental envolve o uso das ideias estatísticas para realizar um estudo. Relaciona-se ao reconhecimento de que a realização de uma pesquisa não se fundamenta nas experiências pessoais, mas em ferramentas que conduzam a coleta, o tratamento e a interpretação dos dados.

Finalmente, a quarta dimensão, a disposição, está relacionada a qualidades pessoais, como curiosidade e questionamento, engajamento, imaginação, ceticismo, raciocínio lógico e disposição para aprender.

Entendemos que o pensamento estatístico está presente nos modos de agir, nas posturas e atitudes dos indivíduos, já que seus elementos permeiam todas as etapas de uma investigação. 
Percebemos que essas competências não priorizam um estudo isolado de métodos e conteúdos estatísticos e sim o oposto, a significação de seus conceitos e uma reflexão do uso de suas ferramentas nos meios de comunicação. Por meio delas, há a preocupação em encorajar o estudante a perceber o papel que as variáveis desempenham na construção de um modelo e olhar para o processo estatístico como um todo, considerando a melhor forma de obter e analisar dados.

\section{A competência crítica e suas articulações com as demais competências}

Em relação à competência crítica, Skovsmose (2014) a define baseado em diversas características: o diálogo, a democracia, o conhecimento reflexivo, entre outras. Assim, a competência crítica é exercida somente se no ambiente educacional se trabalhar o diálogo entre os alunos e com o professor, se houver atitudes democráticas em sala de aula, se o conhecimento inspirar reflexão. Outro aspecto fundamental para se desenvolver a competência democrática é trazer para a aula problemas do cotidiano da comunidade e problemáticas sociais que envolvam a Matemática em sua argumentação. Para tanto, Skovsmose (op. cit.) defende o trabalho pedagógico considerando uma distância crítica do currículo, o trato da Matemática como forma de empoderar os estudantes enquanto cidadãos, o envolvimento da tecnologia no processo educacional, uma educação problematizadora, mas que não se restringe à resolução de problemas.

O processo de ensino-aprendizagem deve ser orientado em direção à meta de prover os estudantes com oportunidades para eles desenvolverem a competência crítica como uma forma de qualificação necessária para sua participação na promoção de processos de democratização na sociedade, e isso inclui desenvolver qualificações de competência e capacidade de lidar com criatividade com os problemas cotidianos da sociedade, de tal forma que eles podem apoiar processos de democratização na sociedade (Skovsmose, 2014).

Campos (2016) entende que o pensamento estatístico ocorre quando os modelos matemáticos são associados à natureza contextual do problema proposto e o aluno identifica e escolhe adequadamente as ferramentas estatísticas necessárias à sua descrição e interpretação. Skovsmose (2014) e Giroux (1997) citam esse aspecto como fundamental para o desenvolvimento da competência crítica.

Outra característica que Campos (2007) comenta sobre o pensamento estatístico é a ideia de prover a habilidade de enxergar o problema estatístico de maneira global, com suas interações 
e seus porquês, entender suas diversas relações e o significado das variações, explorar os dados além do que os textos prescrevem e gerar questões e especulações não previstas inicialmente. Isso está bastante de acordo com o pensamento reflexivo, pois valoriza os questionamentos, a confiabilidade dos resultados etc. Além disso, tende a estimular a criatividade, conforme nos orienta Skovsmose (2014).

Em relação ao raciocínio estatístico e suas interfaces com a competência crítica, Campos (2007) pondera:

Para desenvolver o raciocínio estatístico, destacamos que os problemas de Estatística devem começar com um questionamento e terminar com uma opinião, que espera-se que seja fundamentada em certos resultados práticos. Os julgamentos e as conjecturas expressos pelos estudantes não devem ser caracterizados como certos ou errados, e sim analisados quanto à qualidade de seu raciocínio, adequação e métodos empregados para fundamentar as evidências. Novamente vemos aqui uma adequação com os princípios da rejeição à ideologia do falso-verdadeiro, valorização do aspecto crítico (Skovsmose), valorização da pedagogia da escrita, além de dar voz ao estudante (Giroux), estimulando a reflexão (Campos, 2007, pp. 105-106).

Quanto à Literacia, Campos (2007) mostra que ela tem a ver com a capacidade de argumentar, de se expressar segundo uma linguagem própria da Estatística, mas também expressa a capacidade de debater os conceitos inseridos num contexto de discussão social e valoriza o desenvolvimento de atitudes de questionamento nas quais se aplicam conceitos mais sofisticados para contradizer alegações que são feitas sem fundamentação estatística apropriada. Isso tem ligação com o conhecimento reflexivo que defende a preparação dos alunos para uma vida social, incentivando-os a perceber, entender, julgar e aplicar os conceitos matemáticos em sua vida cotidiana, que é a base da competência crítica.

Com essas ponderações, vemos que a literacia, o raciocínio e o pensamento estatísticos estão imbricados com a competência crítica. Skovsmose (2014) afirma que a Educação Matemática pode e deve contribuir para o processo de formação do estudante por meio de uma perspectiva crítica e reflexiva. Ele explica que é possível refletir sobre a Matemática, com a Matemática e por meio de Matemática. Perin (2019), estende essa ideia para a Educação Estatística Crítica, que ao abarcar as competências apresentadas, permite outros olhares para os fatos, novas reflexões e formas de enxergar o mundo, vendo outras possibilidades de atuação 
nele, com base na análise dos obstáculos que devem ser superados, compreendendo assim possibilidades transformadoras da experiência.

Perin (2019) aprofunda o estudo da competência crítica no âmbito da Educação Estatística, mostrando que ela ocorre segundo duas concepções: a crítica epistemológica e a crítica sociopolítica. A autora aponta que a crítica sociopolítica se faz presente quando o aluno, em seu discurso, é capaz de refletir sobre seu próprio comportamento, sobre suas condutas, percebendo de que forma ele pode contribuir com suas ações para melhorar o mundo. Reflexões de ordem ética, relacionadas ao respeito, à cooperação, à tomada de consciência sobre sua ação, "proporcionando mudanças de atitude, de criação de disposições democráticas do qual se possa substituir hábitos de passividade por hábitos de participação e ingerência” (Perin, 2019, p. 190).

A subcategoria epistemológica da competência crítica emergiu no trabalho de Perin (op. cit.) quando os alunos desenvolveram críticas sobre o conhecimento estatístico, sobre os conceitos trabalhados na disciplina.

[...] os alunos foram confrontados com questões que remetem à tomada de decisões a partir de dados estatísticos. Algumas questões do tipo "Podemos confiar nos dados obtidos por amostras para tirar conclusões sobre toda a população? O que significa tomar decisões baseadas em gráficos e números?" parecem permear a ação de ler e compreender informações que circulam nos meios de comunicação (Perin, 2019, p. 195).

A autora pontua que quando os alunos fazem questionamentos do tipo Quem fez? Como fez? Respeitou todos os cuidados?, demonstram ter compreendido que a Estatística não é livre da influência ideológica e que pode haver interesses de grupos sociais subjacentes às informações com as quais nos deparamos cotidianamente.

Essas observações também remetem à literacia estatística, pois os alunos reconhecem a relevância de articular conhecimentos conceituais sobre o processo de amostragem para verificar se determinadas conclusões podem ser tiradas com base nas informações disponíveis. Eles não só reconheceram essa importância, como também destacam a necessidade de levantar perguntas críticas a esse respeito (Perin, 2019, p. 195).

Novamente vemos nas palavras da autora a convergência entre essa categoria da competência crítica com a literacia.

\section{A modelagem matemática}


A modelagem matemática desenvolvida com base na Educação Matemática tem sido realizada no Brasil desde a década de 1970. Diferentes concepções foram apresentadas desde então, as quais estão fortemente relacionadas com o objetivo que se pretende enfatizar ao se desenvolve-la no ambiente educacional. De forma geral, busca-se favorecer um ensino de Matemática partindo da necessidade dos envolvidos, de seus interesses, de uma forma na qual os alunos constroem seus conhecimentos (Burak, 2019).

Para D’Ambrósio (1986), a modelagem matemática é um processo muito rico para a sala de aula de Matemática e culmina com a solução efetiva de um problema real e não com a simples resolução formal de um problema artificial. Sendo assim, a prática da modelagem matemática incentiva os alunos para a pesquisa na resolução de situações problemas do seu cotidiano.

Aproximando da visão desse autor, Barbosa (2001) defende que a modelagem é um ambiente de aprendizagem no qual os alunos são convidados a indagar e/ou investigar, por meio da Matemática, situações oriundas de outras áreas da realidade, cujo objetivo é alcançar um olhar crítico para a Educação Matemática. Valoriza-se mais as interações durante o processo de modelagem do que os resultados. Nessa mesma direção, Meyer, Caldeira e Malheiros (2011) defendem a vinculação entre a modelagem e uma intenção de educar matematicamente, pois entendem a Matemática como um conjunto de regras e convenções que são estabelecidas dentro de determinado contexto social, histórico e cultural, permeadas pelas relações de poder, diferentemente daquela ciência vista como uma simples descoberta. Os referidos autores almejam, por meio dela, ensinar Matemática de modo que os alunos, como agentes ativos, criem mecanismos de reflexão e ação, buscando desenvolver o senso crítico, a capacidade de resolver situações problemas do cotidiano.

Já para Bassanezzi (2011) e Biembengut e Hein (2013), o objetivo principal é criar condições para que o aluno desenvolva a criatividade matemática de forma que aprendam a fazer modelos matemáticos, aprimorando seus conhecimentos. Para esses autores, a construção dos modelos é primordial para que se caracterize o desenvolvimento de atividade de modelagem matemática.

Burak (1992) a compreende como uma metodologia de ensino e aprendizagem, a qual possui dois princípios fundamentais: 1) o interesse do grupo; 2) a obtenção e informação de dados do ambiente no qual se encontra o interesse do grupo. Dessa forma, "a Modelagem Matemática constitui-se em um conjunto de procedimentos, cujo objetivo é estabelecer um 
paralelo para tentar explicar matematicamente os fenômenos presentes no cotidiano do ser humano, ajudando-o a fazer predições e a tomar decisões” (Burak, 1992, p. 62).

A modelagem, como uma estratégia para o ensino de Matemática, tem os encaminhamentos para as atividades sugeridos com base em cinco etapas, conforme Burak (2004): 1) escolha do tema; 2) pesquisa exploratória; 3) levantamento do(s) problema(s); 4) solução do(s) problema(s) e o desenvolvimento de conteúdos e da Matemática relacionada ao tema; 5) análise crítica das soluções.

Santos (2015), ao realizar um estudo do tipo estado da arte sobre as pesquisas em Educação Estatística, identificou que a modelagem matemática no ensino e na aprendizagem de Estatística tem se destacado como elaboração de estratégias didáticas e propostas metodológicas nos variados níveis de ensino.

Tendo em vista a notoriedade que o ambiente de modelagem matemática tem alcançado nas pesquisas em Educação Estatística, o que faremos neste artigo será mostrar como uma atividade de modelagem, estruturada de forma a desenvolver as competências de raciocínio e pensamento estatísticos, abarca o desenvolvimento da literacia e, por consequência exercita a competência crítica.

\section{Interfaces entre as etapas da modelagem matemática e as competências estatísticas}

1) Escolha do tema - O processo de modelagem matemática parte de temas propostos pelos alunos que devem estar trabalhando em grupos. Os temas podem envolver esportes, atividades industriais, econômicas e comerciais, prestação de serviços, meio ambiente, saúde, questões sociais entre outros. As discussões proporcionadas nessa etapa podem levar ao desenvolvimento do raciocínio estatístico, mais especificamente o raciocínio sobre os dados, pois os alunos reconhecerão a necessidade dos dados, seus diferentes tipos, os quais produzem diferentes formas de recolhas e de tratamento. É nessa etapa que os alunos farão questionamentos do tipo: Como nossas questões iniciais serão respondidas? Como vamos coletar esses dados? Como deverão ser organizados de forma que nos ajudem a compreender o que está sendo investigado?

Já em relação ao pensamento estatístico, nessa primeira etapa há uma maior evidência da primeira dimensão descrita por Wild e Pfannkuch (1999), o ciclo investigativo. É nesse momento que os alunos começam a visualizar todas as etapas de uma investigação estatística, pois escolher o tema requer definir o problema, planejar no sentido de identificar as variáveis 
envolvidas, discutir o plano de amostragem e como os dados deverão ser organizados, além compreender o que se busca explorar, elaborar hipóteses e generalizações. Ainda que não haja o domínio dos conteúdos estatísticos envolvidos em cada uma dessas ações, é nesse primeiro momento que ocorrem discussões no sentido de o aluno perceber a necessidade e a importância das ferramentas estatísticas. Entendemos que é nesse momento também que o professor deve intervir como mediador, a fim de encorajar os alunos a se envolverem numa atividade investigativa.

Ao raciocinar sobre dados e elaborar um plano para coleta de dados, alguns elementos do modelo de conhecimento estatístico proposto por Gal (2002) são acionados, como a habilidade de letramento, pois requer a habilidade de relacionar ideias e combinar informações. O indivíduo tem que associar a informação textual (conhecimento estatístico) com o extratextual (o tema que pretende investigar). Segundo o referido autor, essa habilidade é essencial para que o indivíduo seja capaz de dar sentido aos conceitos estatísticos. Ele tem de discernir entre o que constitui ou não uma boa amostra de modo a validar o plano que está sendo elaborado. Iniciase um pensamento crítico sobre a aplicação das ferramentas estatísticas no contexto do problema, característica essencial da literacia estatística. Como isso se faz por meio do diálogo entre alunos e alunos e entre alunos e professor, observamos o exercício competência crítica epistemológica.

2) Pesquisa exploratória - Essa etapa da modelagem se configura como importante para o desenvolvimento da experiência de campo, ajudando a gerar um comportamento mais atento, mais sensível e mais crítico, atributos importantes na formação de uma postura investigativa. Assim, ao trabalhar um tema, procura-se identificar as várias dimensões ou aspectos que compõem a realidade. Por exemplo, ao se trabalhar o tema indústria cerâmica, explora-se aspectos que constituem essa realidade, sejam eles políticos, sociais, econômicos, estruturais, entre outros. Os dados coletados são de natureza qualitativa e quantitativa. Nessa segunda etapa pode-se desenvolver dois tipos importantes de raciocínio. Novamente o raciocínio sobre os dados, mas agora de maneira mais intensa de forma que o aluno, ao trabalhar nessa etapa, seja capaz de categorizar dados como quantitativos e qualitativos e suas subclassificações. Além desse tipo de raciocínio, tem-se, também, o raciocínio sobre as amostras, pois obter dados requer uma discussão sobre o plano de amostragem. 
No que se refere ao pensamento estatístico percebe-se nessa etapa fortes relações com a segunda dimensão do pensamento estatístico, denominada por Wild e Pfannkuch (1999) de ciclo interrogativo, pois é nesse momento que se levanta questões do nível macro e micro da pesquisa. Conforme descrito por Burack (2019), é nessa etapa que se procura identificar as várias dimensões ou aspectos que compõem a realidade, e fazer isso requer a geração de ideias, requer buscar informações, interpretar, criticar e julgar, ações que compõem a segunda dimensão do pensamento estatístico. Conforme dissemos, é nessa etapa que os alunos reconhecem a necessidade dos dados de forma mais categórica, além de desenvolver planos mais elaborados de coleta de dados. Tal fato abarca uma outra dimensão do pensamento estatístico, denominada tipos fundamentais de pensamento estatístico — reconhecimento da necessidade dos dados, transnumeração (mudança de representação para possibilitar o entendimento da informação), raciocínio com modelos estatísticos, interagindo a estatística com o contexto. Essa dimensão está associada à consciência de que conclusões sobre um determinado contexto só podem ser tiradas com base em uma análise cuidadosa e sistemática.

Ao exercitar aspectos do raciocínio e do pensamento estatísticos ligados a coleta de dados, os alunos começam o exercício de distinguir uma população de uma amostra. Além disso, é nesse momento que eles começam a refletir sobre a representatividade de uma amostra e começam a indagar e buscar por metodologias para evitar o enviesamento das amostras de forma que essas possam representar a população em estudo. Cabe também ao professor fazer essa mediação, colocando os seguintes questionamentos: Qual é a população: Como deverá ser selecionada a amostra de modo a ser representativa? É necessário utilizar uma amostra estratificada? É permitido a participação voluntária em pesquisas?

Vimos que segundo Campos, Wodewotzki e Jacobini (2011) o entendimento de conceitos e a apropriação de vocábulos constituem a literacia estatística. Conceitos como censo, amostra, amostragem, tipos de amostragem são trabalhados nessa etapa. Dos elementos propostos no modelo de Gal (quadro 1) percebe-se de forma mais evidente, o conhecimento estatístico, nesse acaso os relacionados ao processo de amostragem. Também notamos a presença do conhecimento contextual, pois há a necessidade de conhecer o contexto e suas características para elaborar planos de coleta de dados que sejam adequados à sua realidade. Mas, conforme discutido por Perin e Wodewotzki (2019) não se trata apenas de saber-fazer, mas de compreender o quê, como e por que coletar de determinada maneira, e, ao fazê-lo, ter ciência 
das implicações do que se fez. Nesse contexto, vemos aqui a presença de um outro elemento, que é o posicionamento crítico. O aluno pratica a competência crítica epistemológica porque requer a problematização dos conteúdos intelectuais e demanda a compreensão do objeto em estudo. O aprendizado do conteúdo está associado à tomada de consciência do seu uso em situações cotidianas. De forma análoga, ao se trabalhar a exploração dos aspectos que constituem a realidade que está sendo estudada, sejam eles políticos, sociais, econômicos, estruturais, etc., percebemos a atuação da competência crítica sociopolítica.

Por entendermos a $3^{\mathrm{a}}$-Levantamento do problema - e $4^{\mathrm{a}}$ - Resolução do problema e o desenvolvimento do conteúdo matemático no contexto do tema - etapas, que são muito próximas no que se diz respeito a aspectos do raciocínio, pensamento e letramento estatístico vamos tratá-las de forma simultânea. O levantamento do problema é a terceira etapa do método de modelagem e é feito com base nos dados coletados na etapa da pesquisa exploratória. Por se tratar de problemas elaborados com base nos dados coletados na pesquisa de campo, eles apresentam, geralmente, caráter genérico, por isso estimulam a pesquisa e requerem a organização dos dados favorecendo a compreensão mais geral de uma determinada situação. Diferentemente das situações apresentadas nos livros textos, na modelagem matemática, são os problemas que determinam os conteúdos a trabalhar. Pautados pelo contexto do tema, podem ser desenvolvidos vários conteúdos matemáticos, estatísticos e não matemáticos provenientes dos dados coletados e das hipóteses levantadas pelo professor e/ou pelo grupo.

São nessas etapas que ocorrem a transição entre linguagens diferentes; a primeira transição é da linguagem natural para a linguagem sistemática, que ocorre quando uma situação da realidade é transformada em informações; a segunda é a transição da linguagem sistemática para a linguagem matemática, que ocorre quando as informações são transformadas por meio de hipóteses simplificadas em um modelo matemático/estatístico. Nelas é que são usadas todas as ferramentas matemáticas/estatísticas disponíveis. Na resolução de um problema ou de uma situação-problema, os conteúdos matemáticos ganham importância e significado. As operações, as propriedades e os diversos campos da Matemática que se destacam nessa fase, conferem significados aos conteúdos. Adicionalmente, questões não matemáticas oriundas dos dados podem merecer atenção ao envolver assuntos como meio ambiente, problemas sociais, políticos, culturais e econômicos, entre outros. Por se tratar de problemas abertos pode acontecer que um conteúdo necessário à resolução do problema ainda não tenha sido apresentado ao aluno. É, 
então, um momento importante para que o professor, na condição de mediador, ofereça ao aluno a aquisição desse conhecimento.

Essas etapas são caracterizadas pela tradução do contexto por meio dos dados coletados. Para que isso ocorra é necessário a organização dos dados em tabelas e gráficos, a determinação das medidas de posição central e de dispersão, e o estabelecimento de relações entre algumas variáveis envolvidas.

Com isso, trata-se de etapas oportunas ao desenvolvimento dos seguintes tipos de raciocínio: sobre representação de dados, sobre medidas estatísticas e sobre associação. Esses tipos de raciocínio estão vinculados à terceira dimensão do pensamento estatístico, denominada tipos de pensamento, a qual é caracterizada pela adequação das ferramentas estatísticas ao contexto investigado. Está também associado a um exercício de transnumeração, que corresponde à exploração, análise e apresentação de números em formas de tabelas, gráficos e medidas, sejam elas de resumo ou de dispersão. São nessas etapas que ocorrem também a consideração sobre a variação. Englobar isso tudo requer do estudante uma propensão para procurar significados mais profundos, sendo lógico, aberto e observador. Por isso, há que se estar envolvido com as ideias que estão associadas aos dados e ao contexto, e tais posicionamentos compõem a quarta dimensão do pensamento estatístico, assim como caracteriza a literacia estatística.

Nessa fase, ao representar e resumir as informações e traduzir em números as características do contexto estudado, o aluno exercitará a capacidade de ler e interpretar dados contidos em tabelas e gráficos, a fim de comunicar as informações ali expressas. Certamente, ao passar por essas etapas, os alunos se questionarão sobre a forma mais adequada para representar os dados, assim como também se abrirá espaço para o aluno reconhecer e considerar um outlier no cálculo da média, mediana e moda e sugerir a medida mais adequada para representar aquele conjunto de dados. Percebe-se que nessas etapas o aluno pode adquirir muito mais que habilidades numéricas para o exercício pleno da cidadania, conforme discutido por Gal (2002) ao discorrer sobre a literacia estatística. De acordo com o modelo de letramento proposto pelo autor citado, compreendemos que nessa fase todos os elementos do conhecimento e de disposição são acionados. 
Há que se considerar que o professor tem um papel fundamental nessa etapa na qualidade de mediador, conduzindo e encorajando os alunos a trabalhar mais intensamente com os diversos tipos de raciocínio e com o letramento.

5) Análise crítica das soluções — Essa etapa da modelagem é caracterizada pelo revisitar das etapas anteriores, especialmente rica para analisar e discutir as soluções encontradas. É momento de considerar e avaliar as hipóteses construídas na fase de levantamento dos problemas. Possibilita tanto o aprofundamento acerca dos aspectos matemáticos como dos não matemáticos envolvidos no tema. Sob o aspecto da Matemática/Estatística, analisa-se a coerência e a consistência lógica das soluções encontradas. É nesse estágio que se discutem os cuidados com a linguagem e os limites no que se refere à aplicação da Estatística para o entendimento de uma situação cotidiana. Tão importante quanto trabalhar os aspectos matemáticos das situações, os não matemáticos são essenciais para construção e consolidação de valores e de atitudes permanentes e essenciais para a formação do aluno. Assim, dizemos que essa etapa é valiosa para a retomada dos diferentes tipos de raciocínio explorados em cada uma das fases anteriores. Isso implica o momento de checar os pontos a favor e contra às conclusões que estão sendo realizadas, de questionar a confiabilidade das informações, utilidade das ideias e geração de novas ideias.

É nessa etapa também que se busca fazer generalizações sobre as características de uma população com base em afirmações contidas na amostra, reconhecendo que há métodos para isso, o que implica que essa etapa também favorece o desenvolvimento do raciocínio sobre incerteza e inferência. Isso tudo requer raciocinar com os modelos estatísticos e interagir a Estatística com o contexto, mas, para isso, os alunos devem estar curiosos, abertos e atentos. Tais ações envolvem as quatro dimensões do pensamento estatístico, pois entendemos que é nessa etapa que o aluno é convidado a olhar de maneira mais sistemática para o processo de investigação estatística como um todo.

Resumidamente vimos que essa etapa é marcada pelos atos de avaliar, julgar, questionar e associar conceitos matemáticos e estatísticos à leitura de mundo, ou seja, é o momento de refletir e ressignificar as ações desenvolvidas, além de abrir espaço para que novos conteúdos sejam explorados. Skovsmose (2014) colocou a reflexão como um dos elementos chave para a competência crítica. Fazendo um paralelo com Skovsmose (op. cit.) vemos que nessa etapa é possível estabelecer reflexões sobre a Estatística, isso se dá no momento em que procuramos 
validar os modelos construídos, de forma que possam representar a situação em estudo. Pelo fato de as atividades de modelagem matemática referirem-se a situações de ordem econômica, industrial, social, ambiental, comercial, esportiva, etc., isso permite fazer reflexões de diferentes naturezas à luz do conhecimento estatístico.

Vemos, assim, forte sintonia com o que caracteriza a literacia estatística e a competência crítica, na medida em que o indivíduo apropria-se de um conhecimento conceitual da Estatística e de uma postura crítica e reflexiva do seu uso nos diferentes contextos, ou seja, é chamado a exercer uma reflexão acerca das implicações da sua aplicabilidade.

\section{Considerações finais}

Sintetizamos no quadro 2 a discussão realizada sobre as competências estatísticas nas etapas propostas por Burak (2019) para a Modelagem Matemática. Nele, buscamos evidenciar os tipos de raciocínio e dimensões do pensamento estatístico mais marcantes em cada etapa. Além disso, mostramos os componentes do letramento estatístico que se fazem presentes quando se realiza uma atividade modelagem matemática.

Quadro 2: Relações entre etapas da Modelagem Matemática, tipos de raciocínio estatístico, elementos do pensamento estatístico e elementos do letramento abarcado em cada etapa

\begin{tabular}{|c|c|c|c|}
\hline $\begin{array}{c}\text { Etapas da Modelagem } \\
\text { Matemática }\end{array}$ & Tipos de Raciocínio & $\begin{array}{c}\text { Dimensão do } \\
\text { Pensamento Estatístico }\end{array}$ & $\begin{array}{c}\text { Componentes do } \\
\text { Letramento Estatístico }\end{array}$ \\
\hline $\begin{array}{c}1^{\mathrm{a}} \text { Etapa - Escolha do } \\
\text { tema }\end{array}$ & $\begin{array}{l}\text { Raciocínio sobre os } \\
\text { dados }\end{array}$ & Ciclo Investigativo & $\begin{array}{l}\text { Habilidades de } \\
\text { letramento }\end{array}$ \\
\hline $\begin{array}{c}2^{\text {a }} \text { Etapa - Pesquisa } \\
\text { Exploratória }\end{array}$ & $\begin{array}{c}\text { Raciocínio sobre os } \\
\text { dados } \\
\text { Raciocínio sobre } \\
\text { amostras }\end{array}$ & $\begin{array}{c}\text { Ciclo Interrogativo } \\
\text { Tipos fundamentais do } \\
\text { pensamento estatístico }\end{array}$ & $\begin{array}{c}\text { Conhecimento estatístico } \\
\text { Conhecimento } \\
\text { Contextual }\end{array}$ \\
\hline $\begin{array}{c}3^{\text {a }} \text { Etapa - Levantamento } \\
\text { dos problemas } \\
4^{\text {a Etapa - Resolução }} \\
\text { do(s) problema }(\mathrm{s}) \text { e } \\
\text { desenvolvimento do } \\
\text { conteúdo matemático no } \\
\text { contexto do tema }\end{array}$ & $\begin{array}{l}\text { Raciocínio sobre } \\
\text { representação de dados } \\
\text { Raciocínio sobre } \\
\text { medidas estatísticas } \\
\text { Raciocínio e sobre } \\
\text { associação }\end{array}$ & $\begin{array}{l}\text { Ciclo Investigativo } \\
\text { Tipos gerais e } \\
\text { fundamentais do } \\
\text { pensamento estatístico } \\
\text { Disposição }\end{array}$ & $\begin{array}{c}\text { Habilidades de } \\
\text { letramento } \\
\text { Conhecimento estatístico } \\
\text { Conhecimento } \\
\text { Matemático } \\
\text { Questionamento Crítico }\end{array}$ \\
\hline $\begin{array}{c}5^{\mathrm{a}} \text { Etapa - Análise crítica } \\
\text { das soluções }\end{array}$ & $\begin{array}{c}\text { Raciocínio sobre } \\
\text { representação de dados } \\
\text { Raciocínio sobre } \\
\text { medidas estatísticas } \\
\text { Raciocínio e sobre } \\
\text { associação } \\
\text { Raciocínio sobre } \\
\text { incerteza }\end{array}$ & $\begin{array}{l}\text { Ciclo investigativo } \\
\text { Ciclo interrogativo } \\
4 \text { dimensões do } \\
\text { pensamento } \\
\text { Disposição }\end{array}$ & $\begin{array}{c}\text { Crenças e atitudes } \\
\text { Posicionamento Crítico }\end{array}$ \\
\hline
\end{tabular}

Fonte: Elaboração dos Autores 
Note-se que os tipos de raciocínio, os elementos do pensamento estatístico e os componentes do letramento não pertencem exclusivamente a uma única etapa da atividade de modelagem matemática. No Quadro 2, nós apenas destacamos aquilo que é mais acentuado em cada etapa, tendo em vista que o processo investigativo é dinâmico e marcado pela retomada das etapas já vivenciadas, o que pôde ser observado na figura 3.

Adicionalmente, mostramos em nossa análise a presença da competência crítica, seja ela epistemológica ou sociopolítica, nas diversas etapas da modelagem matemática. Isso deve ainda ser conjugado com os elementos de disposição apresentados por Gal (quadro 1), que são as crenças e atitudes, além do posicionamento crítico. A atividade de modelagem propicia um rico momento para exercitar a reflexão sobre as problemáticas sociais envolvidas no contexto do problema que está sendo trabalhado. Tais reflexões devem ser encorajadas pelo professormediador ao longo das diversas etapas, sendo que a discussão e o diálogo, assim como a democratização do ambiente da sala de aula, são fundamentais para o pleno desenvolvimento da competência crítica, conforme a descrevemos.

Por fim, entendemos que a estratégia pedagógica da modelagem matemática, nos termos definidos por Burack (2019), favorece sobremaneira o desenvolvimento das competências do pensamento, raciocínio e letramento estatísticos, além da competência crítica epistemológica e sociopolítica. Tal interação ficou evidenciada ao longo da descrição das etapas da modelagem, mas entendemos que a sua intensidade pode variar conforme o professor-mediador estiver consciente das potencialidades das atividades e puder valorizar as atitudes e posturas requeridas dos estudantes para o bom desenvolvimento das competências citadas.

\section{Referências}

Almouloud, S. A., \& Silva, M. J. F. (2019). Construção do referencial teórico de uma pesquisa educacional. In G. P. Oliveira (org.), Pesquisa em educação e educação matemática: um olhar sobre a metodologia, (49-82). Curitiba; CRV.

Barbosa. J. C. (2001). Modelagem na Educação Matemática: contribuições para o debate teórico. Anais da Reunião Anual da ANPED, 24, 2001, Caxambu: ANPED.

Bassanezi, R. C. (2011). Ensino-aprendizagem com modelagem matemática: uma nova estratégia. São Paulo: Contexto.

Biehler, R., Frischemeier, D., Reading, C., \& ShaughnessY, M. (2018). Reasoning about data. D. Ben-Zvi; K. Makar; J. Garfield (Orgs.) International Handbook of Research in Statistics Education, (138-186). Gewerbestrasse: Springer International. 
Biembengut, M. S., \& Hein, N. (2013). Modelagem matemática no ensino. $5^{\text {a }}$ ed. São Paulo: Contexto.

Burak, D. (1992). Modelagem matemática: ações e interações no processo de ensino aprendizagem. 460f. Tese (Doutorado em Educação) — Faculdade de Educação. Campinas: UNICAMP.

Burak, D. (2004). Modelagem Matemática e a sala de aula. Anais do I EPREM: Modelagem Matemática: práticas, críticas e perspectivas de Modelagem na Educação Matemática, 208-222. Londrina: UEL.

Burak, D. (2019). A Modelagem Matemática na perspectiva da Educação Matemática: olhares múltiplos e complexos. Educação Matemática sem Fronteiras, 1 (1), 96-111 Chapecó: UFFS.

Campos, C. R. (2007). A Educação Estatística: uma investigação acerca dos aspectos relevantes à didática da Estatística em cursos de graduação. 256f. Tese (Doutorado em Educação Matemática) — Rio Claro: Instituto de Geociências e Ciências Exatas UNESP.

Campos, C. R. (2016). Towards Critical Statistics Education. Saarbrücken, Alemanha: Lambert Academic Publishing.

Campos, C. R., \& Coutinho, C. Q. S. (2019). O problema da amostragem no contexto da educação estatística crítica. Anais da XV Conferência Interamericana de Educação Matemática (1-9). Medellín: Universidad de Medellín. Retirado em 18 de setembro, 2019

de: file:///C:/Users/Usuario/Downloads/CIAEMColmbiaOproblemadaamostragemdoconte xtodaedestcrtica.pdf

Campos, C. R., Wodewotzki, M. L. L., \& Jacobini, O. R. (2011). Educação Estatística: teoria e prática em ambientes de modelagem matemática. Belo Horizonte: Autêntica.

Cazorla, I. M., Silva Júnior, A. V., \& Santana, E. R. S. (2018). Reflexões sobre o ensino de variáveis conceituais na educação básica. REnCiMa, 9(2), 354-373.

Coutinho, C. Q. S., \& Campos, C. R. (2018) Perspectivas em didática e educação estatística e financeira: reflexões sobre convergências entre letramento matemático, matemacia, letramento estatístico e letramento financeiro. G. P. Oliveira (org.), Educação Matemática: epistemologia, didática e tecnologia (143-180). São Paulo: Livraria da Física.

Coutinho, C. Q. S., \& Campos, C. R. (2019). Metodologia quantitativa e mista. G. P. Oliveira (Org.), Pesquisa em Educação Matemática: um olhar sobre a metodologia, (83-108). Curitiba: CRV.

D’Ambrosio, U. (1986). Da realidade à ação: reflexos sobre Educação e Matemática. São Paulo: Summus.

Delmas, R. C. (2002). Statistical literacy, reasoning and learning: a commentary. Journal of Statistics Education, 10(3). Disponível em: www.amstat.org/publications/jse/v10n3/chance.html. 
Fiorentini, D., \& Lorenzato, S. (2006). Investigação em Educação Matemática: percursos teóricos e metodológicos. Campinas: Autores Associados.

Gal, I. (2002). Adult statistical literacy: meanings, components, responsibilities. International Statistical Review, 70 (1), 1-25.

Giroux, H. A. (1997). Os professores como intelectuais: rumo a uma pedagogia crítica. Trad. Daniel Bueno. Porto Alegre: Artmed.

Machado, M. B. (2017). Modelagem matemática como ambiente de aprendizagem de Estatística na educação Básica. 155f. Dissertação (Mestrado em Ensino de Matemática) — Porto Alegre: Instituto de Matemática/UFRS.

Meyer, J. F. C., Caldeira, A. D., \& Malheiros, A. P. S. (2011). Modelagem em Educação Matemática. Belo Horizonte: Autêntica.

Ministério da Educação (MEC). (2017). Resolução cne/cp no 2, de 22 de dezembro de 2017. Institui Base Nacional Comum Curricular. Brasília: Diário Oficial República Federativa do Brasil

Perin, A. P. (2019). Educação Estatística Crítica: um estudo das práticas discentes em um curso de tecnologia. 267f. Tese (Doutorado em Educação Matemática). Rio Claro: Instituto de Geociências e Ciências Exatas/UNESP.

Perin, A. P., \& Wodewotzki, M. L. L. (2019). A modelagem matemática: um ambiente para o desenvolvimento do raciocínio estatístico. Caminhos da Educação Matemática em Revista, 9 (2), 158-170.

Pfannkuch, M. (2018). Reimagining curriculum approaches. D. Ben-Zvi, K. Makar; \& J. Garfield (Eds.), (384-406). International Handbook of Research in Statistics Education. Gewerbestrasse: Springer International.

Samá, S. P. (2018). Caminhos trilhados pelo GT12 nas pesquisas em Educação Estatística no Brasil. Anais do VII Seminário Internacional de Pesquisa em Educação Matemática,(112). Foz do Iguaçu: SBEM. Retirado em 10 de junho, 2019, de: http://www.sbemparana.com.br/eventos/index.php/SIPEM/VII_SIPEM/paper/view/54 $7 / 249$

Santos, R. M. (2015). Estado da arte e história da pesquisa em Educação Estatística em programas brasileiros de pós-graduação. 348f. Tese (Doutorado em Educação). Campinas: Faculdade de Educação/UNICAMP.

Skovsmose, O. (2014). Educação Matemática Crítica: a questão da democracia. $3^{\mathrm{a}}$ ed. Campinas: Papirus.

Snee, R. (1990). Statistical thinking and its contribution to total quality. The American Statistician, 44 (2), 116-121.

Snee, R. D. (1999). Discussion: development and use of statistical thinking: a new era. Internacional Statistical Review, 67, 255-258.

Soares, J. A. R. (2017). Modelagem matemática como estratégia de ensino de tópicos de Estatística na formação básica técnica. 172f. Dissertação (Mestrado em Matemática). Arraias: Universidade Federal do Tocantins. 
Trainotti, A. (2019). A Educação Estatística e a modelagem matemática na formação crítica dos estudantes do Ensino Médio de escolas do município de Rio do Sul. 95f. Dissertação (Mestrado em Ensino de Matemática). Porto Alegre: Instituto de Matemática/UFRS.

Wild, C., \& Pfannkuch, M. (1999) Statistical thinking in empirical enquiry. Internacional Statistics Review, 67 (4), 223-265.

Zieffler, A., Garfield, J., \& Fry, E. (2018). What is Statistics Education? D. Ben-Zvi, K. Makar, \& J. Garfield (Org.). International Handbook of Research in Statistics Education, (3771). Gewerbestrasse: Springer International.

Autores:

Andréa Pavan Perin. https://orcid.org/0000-0002-2791-7682. Faculdade de Tecnologia de São Paulo - Brasil. Professora da educação básica desde 2004 e universitária desde 2008. Doutora em Educação Matemática pela UNESP, Mestre em Educação pela Universidade Metodista de Piracicaba, professora associada da Faculdade de Tecnologia de Itapetininga, São Paulo. Linhas de investigação: educação estatística, educação crítica, educação financeira, modelagem matemática e formação de professores. Membro do GT-12 12 (Educação Estatística) da SBEM (Sociedade Brasileira de Educação Matemática).

Celso Ribeiro Campos. https://orcid.org/0000-0001-7371-2437. Pontifícia Universidade Católica de São Paulo - Brasil. Físico e Engenheiro pela UNITAU, mestre em Ensino da Matemática pela PUC-SP, Doutor em Educação Matemática pela UNESP. Professor de Economia Matemática e Econometria no curso de graduação em Ciências Econômicas da PUC-SP. Professor e orientador de mestrado e doutorado em Educação Matemática da PUCSP. Membro do GT-12 (Educação Estatística) da SBEM (Sociedade Brasileira de Educação Matemática). Pesquisador do grupo de pesquisas PEA-MAT da PUC-SP. 